\title{
Evaluation of App-Embedded Disease Scales for Aiding Visual Severity Estimation of Cercospora Leaf Spot of Table Beet
}

\author{
Emerson M. Del Ponte, ${ }^{1}$ Scot C. Nelson, ${ }^{2}$ and Sarah J. Pethybridge ${ }^{3, \dagger}$ \\ ${ }^{1}$ Departamento de Fitopatologia, Universidade Federal de Viçosa, Viçosa, MG 36570-000, Brazil; ${ }^{2}$ Department of Tropical Plant \\ and Soil Sciences, College of Tropical Agriculture and Human Resources, University of Hawaii at Manoa, Honolulu, HI 96822, \\ U.S.A.; and ${ }^{3}$ Plant Pathology \& Plant-Microbe Biology Section, School of Integrative Plant Science, Cornell AgriTech at the New \\ York State Agricultural Experiment Station, Cornell University, Geneva, NY 14456, U.S.A.
}

\begin{abstract}
Two diagrammatic ordinal scales are available in the Estimate app (2017 version) for Cercospora leaf spot (CLS) severity on table beet: $10 \%$ linear (linear-based diagrammatic scale [LIN]) and logarithmic based (Horsfall-Barratt $[\mathrm{HB}]$ ). These allow for estimating severity data of four types depending on the system used. A group of 30 raters assigned percentage severity on 30 photographs of diseased table beet leaves during five rounds first without an aid and then using each of the four rating systems in Estimate. In two, the perceived ordinal score of the HB or LIN scale was assigned where severity of the subject fit best. HB2 and LIN2 involved a second choice of unitary severity within the perceived score interval. There was large variation in unaided ability of

raters to estimate severity: $13 \%$ were accurate (Lin's concordance correlation $[\mathrm{LCC}]>0.9), 23 \%$ were inaccurate $(\mathrm{LCC}<0.7)$, and the remaining had moderate accuracy. Larger disparities between assigned and actual ordinal scores (mostly overestimates) occurred using the LIN compared with the HB. The LIN2 produced the most accurate estimates (Lin's concordance correlation coefficient, $\rho_{c}=0.96$; generalized bias parameter, $C_{b}=0.99$; Pearson's correlation coefficient $r=0.95$ ) and the greatest interrater reliability (overall concordance correlation coefficient and intraclass correlation coefficient $>0.93$ ). The two-step process using the $10 \%$ linear scale is recommended for severity estimates of CLS in table beet.
\end{abstract}

The use of standard area diagrams (SADs) as aids to improve the accuracy and reliability of visual estimates of severity of leaf spotting diseases is becoming a more standard practice based on compelling evidence of their utility (Bock et al. 2010b, 2016a, 2016b; Chiang et al. 2014; Del Ponte et al. 2017; James 1971, 1974; Madden et al. 2007). A recent review of the technology used to develop SADs highlighted characteristics of the assessment aid and methodological trends given the specificities of the various pathosystems and availability of tools, methods, and decisions made by the researcher during SAD development (Del Ponte et al. 2017). The presentation of an SAD has "evolved" from a set including a limited number of black and white hand-drawn diagrams depicting incremental severity values as references to digitally enhanced true color photographs of diseased plant parts. Diagrammatic scales, often mistakenly referred to as SADs, are a variation of the latter, because conceptually, they are a hybrid system of disease scale, with ordinal scores representing a condition or a percentage interval accompanied by one or more SADs representing the interval (Madden et al. 2007).

The characteristics of $>120$ SADs developed to represent diseases affecting foliage and published in the peer-reviewed literature from

${ }^{\dagger}$ Corresponding author: S. J. Pethybridge; sjp277@cornell.edu

Funding: Research was supported by the U.S. Department of Agriculture, National Institute of Food and Agriculture (USDA NIFA) Hatch project NYG-625424 managed by the New York State Agricultural Experiment Station, Cornell University, Geneva, NY; USDA NIFA Smith-Lever project NYG 2017-18-118; and USDA NIFA Hatch project HAW08036-H (accession no. 1010616) managed by the College of Tropical Agriculture and $\mathrm{Hu}-$ man Resources, University of Hawaii at Manoa, HI.

*The $\boldsymbol{e}$-Xtra logo stands for "electronic extra" and indicates that two supplementary figures are published online.

The author(s) declare no conflict of interest.

Accepted for publication 29 November 2018.

@ 2019 The American Phytopathological Society
1991 to 2017 have previously been summarized (Table 2 in Del Ponte et al. 2017). New SADs continue to be developed as stylized images of the symptomatic organ most often depicted in black (lesion) and white (healthy tissue), where each image within the set of diagrams represents a specific percentage severity. In practice, the SADs offer a finite number of diagrams to aid direct severity estimation. Therefore, the rater needs to interpolate values between two images and assign an estimated severity for a specimen with unknown severity. Some of the decisions when developing an SAD involve number of diagrams, incremental scale, minimum and maximum percentage severity typically encountered under field conditions, and the image to use representing a specific severity (Del Ponte et al. 2017).

Enhanced accessibility of cameras and image analysis software, including portable devices, has accelerated the development of more realistic, stylized color representations or diagrams based on photographs of diseased plant organs (Angelotti et al. 2008; Dolinski et al. 2017; Duarte et al. 2013; Rios et al. 2013; Schwanck and Del Ponte 2014). Irrespective of the method used to prepare the SADs, guidelines for best practices to develop and evaluate SADs before adoption have been emphasized (Del Ponte et al. 2017).

Most SADs are static (as a print or digital image), where the individual images of the SADs are displayed in one or two rows (depending on the number of SADs) and placed side by side for ease of comparison and direct severity assignment. To aid visual severity assessments, an interactive plant disease assessment aid app, named Estimate, was developed for the Apple iPad device (Pethybridge and Nelson 2018). In the current version of the app (as of October 2018), the user selects an ordinal score for the specimen following a linear or logarithmic (Horsfall-Barratt [HB]) (Horsfall and Barratt 1945) severity interval - the midpoint severity is represented by an image with severity of that specific grade in the ordinal scale. An alternative is to collect data based on $1 \%$ intervals. If this option is selected, a second screen is displayed, and the user selects the percentage value perceived to be closest to the test subject. For the latter choice, only the original image for the midpoint interval is displayed. The value of Estimate, with its variations in rating systems, in increasing accuracy and reliability of estimates compared with nonaided estimates has not been thoroughly evaluated. For this type of symptom, whether the second step in the estimation sequence (which 
results in increased assessment time) significantly improves accuracy of the estimates when using many ordinal grades following two incremental scales is unknown. The nature of the percentage severity data collected using SADs is also likely to have a substantial impact on the accuracy and reliability of estimates and subsequent selection of the most appropriate statistical analysis tool for nonparametric and parametric data (Madden et al. 2007).

These concepts were explored using percentage severity estimates for a selected model leaf-spotting disease, Cercospora leaf spot (CLS) of table beet (Beta vulgaris L. subsp. vulgaris), caused by Cercospora beticola Sacc (Fig. 1). The disease is a significant constraint to table beet production worldwide (Koike et al. 2010; McKay and Pool 1918; Pethybridge et al. 2017, 2018; Weiland and Koch 2004). CLS symptoms begin as small gray spots on leaves (Fig. 1) that coalesce and may result in complete defoliation (Franc 2010; Koike et al. 2010; Weiland and Koch 2004). The problem is exacerbated in large-scale table beet production requiring mechanized harvesting, because defoliation leads to the inability to harvest using top-pulling machinery, resulting in complete crop loss (Pethybridge et al. 2018; Stivers 2001). To enable research identifying approaches to manage CLS, use of cost- and time-effective methods for assessing severity of CLS is critical. Severity of CLS in sugar beet has been operationally quantified using a range of pathosystem-specific rating scales, including the Kleinwanzlebener Saatzucht (KWS) scale (Kleinwanzleber Saatzucht Ag 1970), a qualitative ordinal scale usually applied at the whole-plot level. The KWS scale ranges from one to nine, where increasing steps in the scale represent changes in severity and disease progress. For example, one indicates no leaf spot symptoms, three indicates lesions found on leaves, five indicates that lesions have coalesced to form larger areas of necrotic leaf tissue, seven indicates that older leaves have shriveled and died and that the disease has spread to the inner leaves, and nine indicates that almost all leaves have died and that new leaves have started to emerge from the root (Kleinwanzleber Saatzucht Ag 1970). The Agronomica

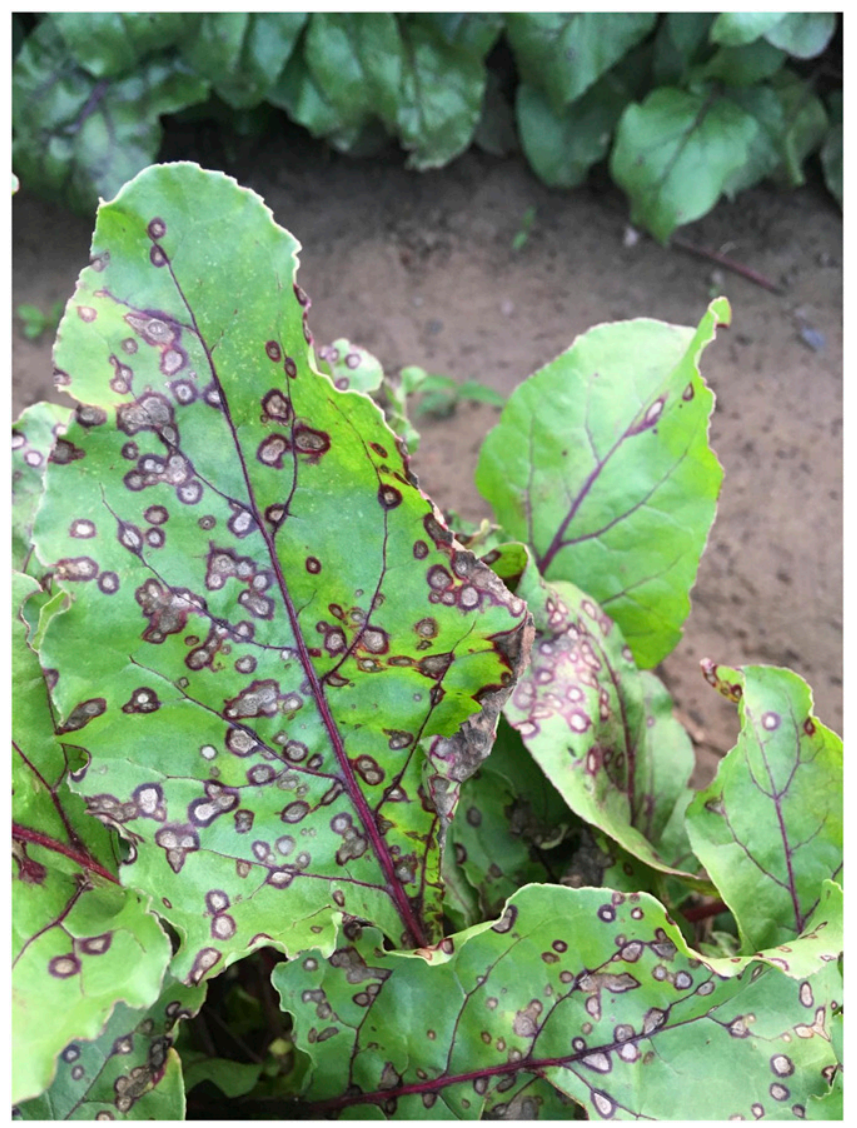

Fig. 1. Cercospora leaf spot symptoms caused by the fungus Cercospora beticola on table beet cultivar Ruby Queen. disease severity index is another qualitative ordinal scale used to assess severity of CLS at the plant scale, and it ranges between zero (healthy) and five (foliage destroyed) in increments of 0.5 (Trueman 2014; Trueman and Burlakoti 2015; Vereijssen et al. 2003). De Coninck et al. (2012) developed a quasiquantitative ordinal scale for CLS on leaves of sugar beet consisting of seven categories covering the range from zero (healthy) to 100 (leaf completely blighted). In addition, May de Mio et al. (2008) developed SADs to aid estimation of CLS in sugar beet. The SADs had six diagrams representing a range of severity up to $23.61 \%$ and using a logarithmic interval (May de Mio et al. 2008). The maximum percentage severity used by May de Mio et al. (2008) is below that frequently observed in table beet fields in New York (Pethybridge et al. 2017).

Visual estimates of the severity of CLS in table beet on a plot scale have relied on logarithmic (Stevenson et al. 2003) and linear (Abawi et al. 2005; Gugino et al. 2008) scales. These assessment methods lack statistical validation of accuracy and reliability of the rater estimates of severity on diseased specimens. Among available assessment methods, counting the number of lesions per leaf is most often used for CLS on table beet and sugar beet (Abawi et al. 2005, 2014; Franc and Stump 2010; Pethybridge et al. 2016, 2017; Stump 2015). However, lesion counting for quantifying severity of CLS in table beet is subject to error because of the inability to distinguish individual lesions when disease is severe, and there is little relationship between lesion counts and percentage severity $(r=0.39$; $P=0.103$ ) (S. J. Pethybridge, unpublished data). Furthermore, counting lesions takes a prohibitive amount of time, also leading to errors from rater fatigue and reduced interrater reliability (Pethybridge and Nelson 2018). Therefore, the objective of this study was to evaluate the effect of the four evaluation systems available in the Estimate app on the accuracy and reliability of estimates of severity using CLS on table beets as a case study.

\section{Materials and Methods}

Two hundred leaves with a range of percentage severities from one small CLS lesion to an entire leaf diseased were collected from eight fields across western New York from July to September 2016. Individual leaf specimens were flattened and photographed using an iPad's eight-megapixel camera with $f / 2.4$ aperture positioned $30 \mathrm{~cm}$ above each specimen within $12 \mathrm{~h}$ as a permanent record (Pethybridge and Nelson 2018). The pixel differentiating and counting algorithm within the Leaf Doctor app (iOS 10) calculated the assumed true percentage severity of CLS on each leaf (Pethybridge and Nelson 2015). Percentage severity was defined by the area affected by disease symptoms/total area of leaf $\times 100$ (Madden et al. 2007; Nutter and Esker 2006; Nutter et al. 1993, 2006).

The standard area disease images represented in the app were selected from the initial 200-leaf sample, with percentage severities representing the midpoint of two scales: the original HB scale but using 10 scores (excluding zero and 100\%) and the 10\% interval scale; these were included in the Estimate app as two primary choices (Pethybridge and Nelson 2018) (Fig. 2). In the Estimate app, the rater has the option to collect percentage severity data as an ordinal scale (one step). In this case, the midpoint of the percentage interval of the selected scale is recorded. Additionally, the Estimate app provides the option to select a percentage value, which is displayed in a $1 \%$ interval but represented by the same image of the midpoint severity, within the chosen interval (Fig. 3 ). In this study, the four different rating systems were evaluated, and they were named $\mathrm{HB}$ and linear-based diagrammatic scale (LIN) for the ordinal (one-step) use of the HB scale and HB2 and LIN2 for the two-step approach.

SADs validation. Thirty inexperienced raters were selected for this study and represented technical staff and students from Cornell University in New York. The validation process consisted of several stages. The innate ability of raters to provide nearest percentage estimates (NPEs) in the absence of an aid was evaluated. This information represented the baseline accuracy for each rater to quantify the gains associated with the use of the aid. The true percentage severities in the image set assessed by the raters ranged from 0.8 to $75.4 \%$. 
Thirteen of the 30 images had percentage severities $<10 \%$. Nine images had percentage severities between 15.7 and $45.7 \%$, and the remainder had percentage severities $>50 \%$. Raters were limited to a maximum time of $10 \mathrm{~s}$ to estimate percentage severity for each image.

The same raters repeated the assessment on four more occasions with a 15-min break between evaluations using the Estimate app on an iPad Air 2 with iOS 11 (Pethybridge and Nelson 2018). Before evaluations, raters received a short ( $\sim 3$-min) written and oral description on the objectives of the study and how to use the Estimate app. During each Estimate-aided assessment, raters selected among 10 images of diseased table beet leaves, each representative of the HB or the $10 \%$ interval scale as described. For each of the two scales, a single-step (ordinal data) process or a two-step (continuous data) process was performed to generate the four datasets recorded through the validation process for each rater. The 10 -s limit to evaluate each image was enforced on each evaluation.

Agreement analyses. For the single-step process of assigning ordinal scores, the actual percentage severity data were categorized within each of the seven grades of the respective scales. The maximum percentage severity in the sample was $75 \%$, and hence, three top grades were missing from the evaluation dataset. A simple percentage agreement or matching the actual grade was calculated with tolerances (number of successive rating categories that should be regarded as rater agreement) of zero, one, and two. A heat map was generated to depict percentage matching (zero tolerance) between estimated and actual severity for each grade of the scales. In addition, the kappa coefficient and respective confidence intervals measured the chance-corrected agreement for two observations. The weighted version was used for ordinal data, with weights decreasing exponentially with distance from the diagonal (quadratic weights) (Sim and Wright 2005). The rel package of R calculated the percentage agreement and the kappa statistics (Martire 2017).

For all four methods, using the estimated percentage severity value (midpoint for $\mathrm{HB}$ and LIN and the unitary severity for
HB2 and LIN2), Lin's concordance correlation (LCC) coefficient $\left(\rho_{c}\right)$ (Lin 1989) was used to evaluate overall agreement (overall accuracy), generalized bias, and precision of the estimates by each rater. LCC coefficient incorporates the precision (Pearson's correlation coefficient $r)$ and a generalized bias parameter $\left(C_{b}\right)$ or the closeness to a concordance line at $45^{\circ}$. The generalized bias parameter incorporates systematic $(v)$ and constant $(\mu)$ bias (Lin 1989; Madden et al. 2007). The LCC from the first unaided assessment was used to classify raters (hereafter defined as "baseline accuracy"). We arbitrarily defined baseline accuracy as poor $\left(\rho_{c}<0.8\right)$, fair $\left(0.8 \leq \rho_{c}<0.9\right)$, and $\operatorname{good}\left(\rho_{c} \geq 0.9\right)$ and explored the LCC statistics in relation to these categories. Analyses of the LCC statistics were conducted in the R statistical environment using the epi.ccc function of the irr package (Gamer et al. 2012).

Effect of evaluation systems. A linear mixed (multilevel) modeling framework evaluated the effect of the evaluation system on each of the three LCC statistics using the lme4 package within R (Baayen et al. 2008; Bates and Sarkar 2007). The fixed and random effects of the model were rating method and raters, respectively. A dummy variable representing unaided and aided assessments was an additional random effect in the model to account for dependency between successive assessments within raters. A Wald test assessed the significance of the fixed effects. The function lsmeans of the lsmeans $\mathrm{R}$ package (Lenth 2016) calculated the least squares means to compare each of the concordance components across assessment methods.

Interrater reliability. Two statistics, the overall concordance correlation coefficient (OCCC) (Barnhart et al. 2002) and the intraclass correlation coefficient (ICC) (Shoukri and Pause 1999), assessed interrater reliability. The OCCC, as used in a previous article on SADs (Correia et al. 2017), is the weighted averaged of all pairwise LCC coefficients (Barnhart et al. 2002).

Data processing and availability. All data processing and analyses as well as graphical work were performed with $\mathrm{R}$ version 3.5.0 (2018-04-23; R Core Team 2016). Texts and scripts were prepared

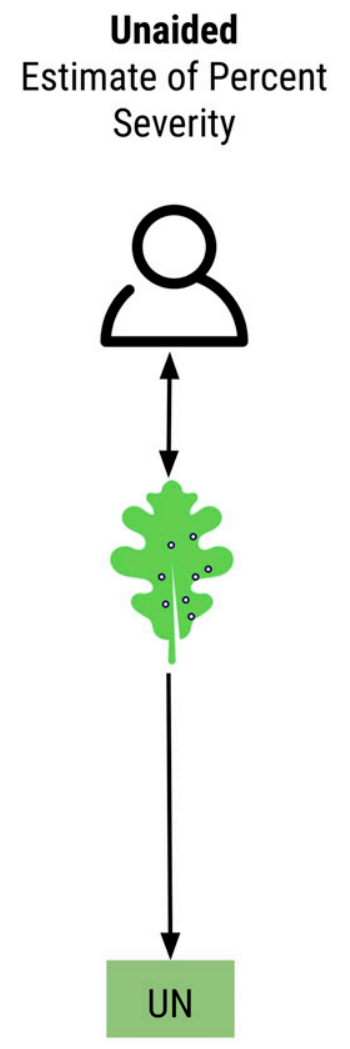

\section{App-Aided Estimates}

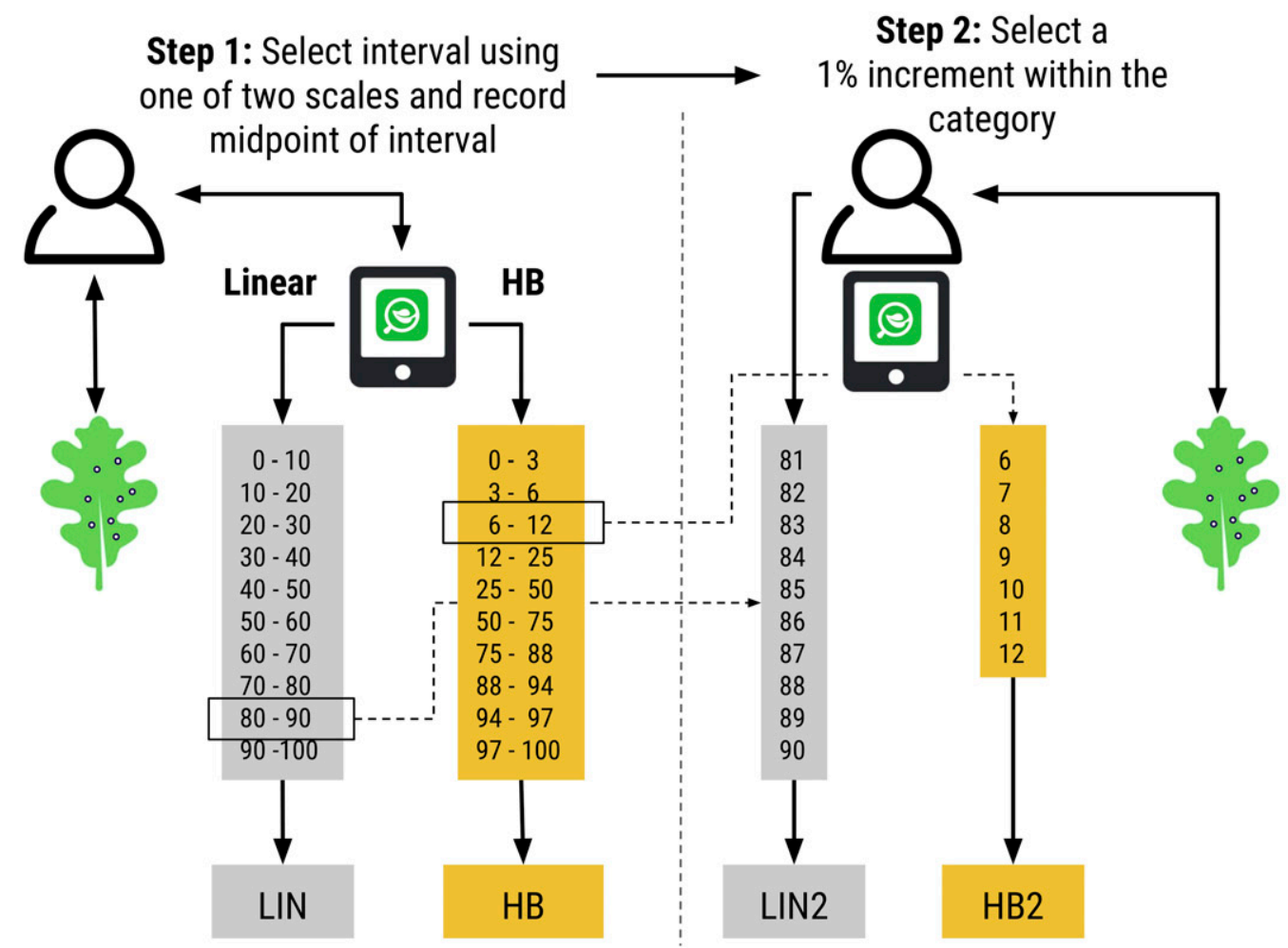

Fig. 2. Workflow diagram outlining the process undertaken by raters to evaluate Cercospora leaf spot severity using four different methods within the Estimate app (2017 version) based on a single- or two-step process of assigning a category of the linear (linear-based diagrammatic scale [LIN]) or Horsfall-Barratt (HB) scale followed by assignment of a severity value perceived as closest to the specimen. UN, unaided. 
as R Markdown documents rendered as a website, where all data and the analyses are documented, reproducible, and openly available for download at https://emdelponte.github.io/paper-estimate-app/. The data are deposited at the Open Science Framework data repository and available at https://osf.io/34nzc/.

\section{Results}

SADs validation. In the first (unaided) evaluation, raters assigned a unique perceived NPE of severity for each of the 30 diseased images. Thirty-eight different NPE values were assigned by each of the 30 raters assessing the specimens (total $=900$ estimates). A strong
A 1 to $9 \%$
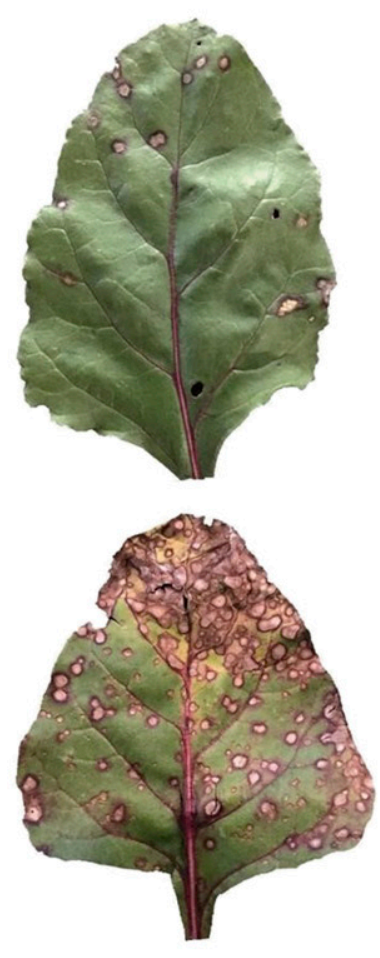

50 to $59 \%$
B
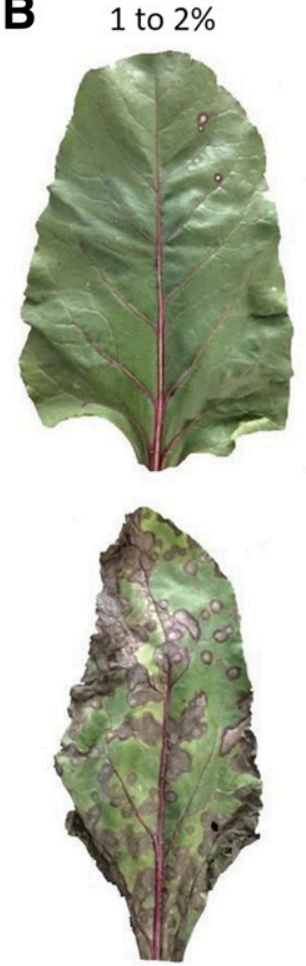

50 to $74 \%$

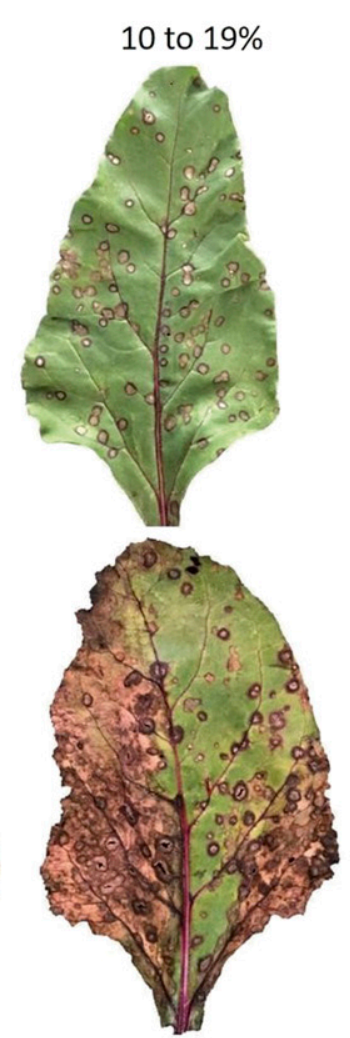

60 to $69 \%$

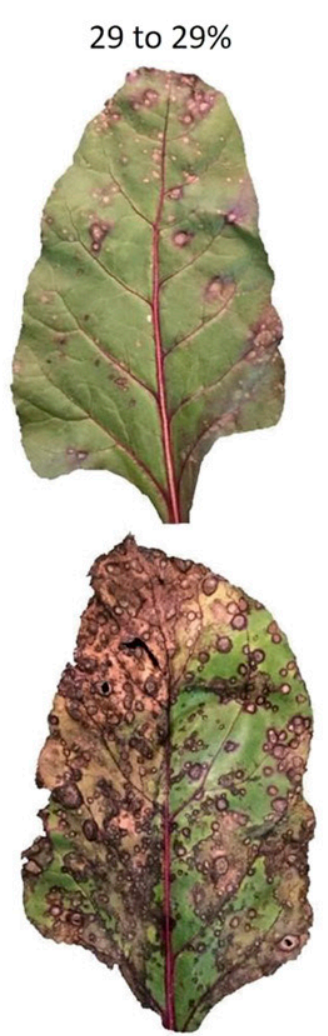

70 to $79 \%$
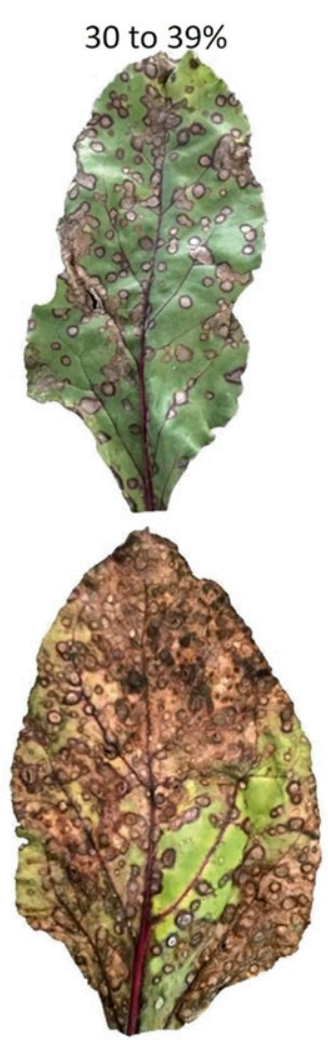

80 to $89 \%$

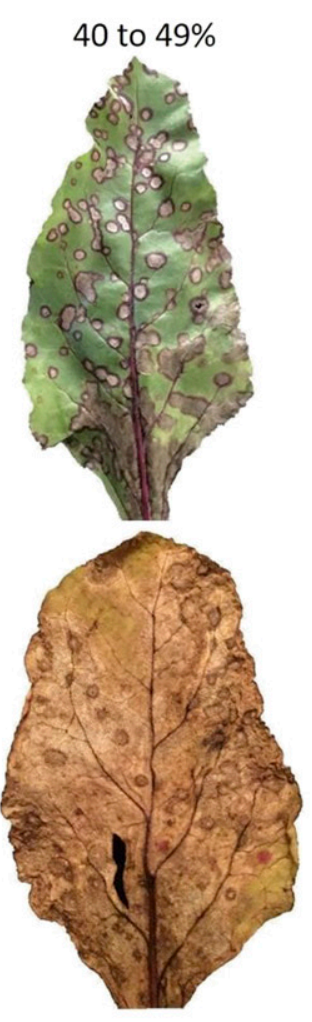

90 to $99 \%$
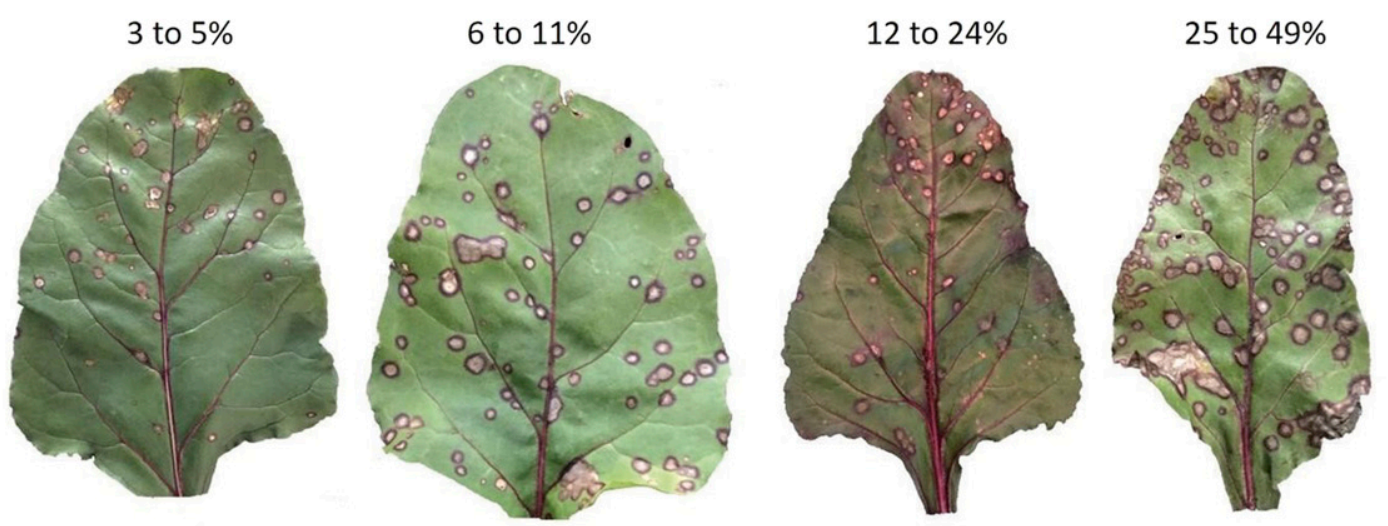

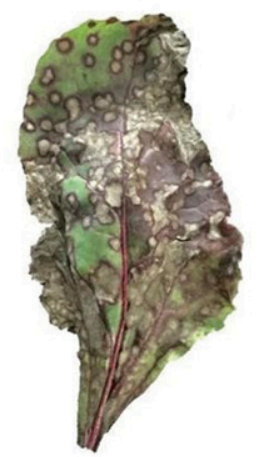

75 to $87 \%$

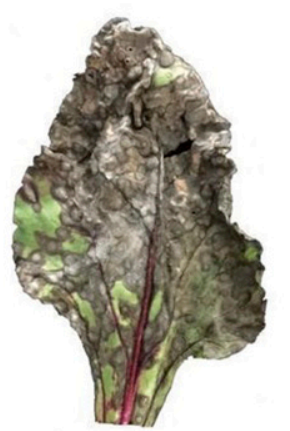

88 to $93 \%$

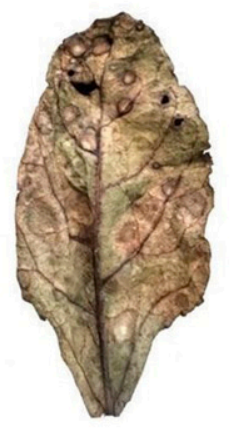

94 to $96 \%$

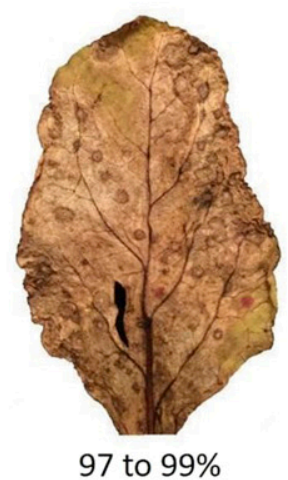

Fig. 3. Standard area diseased image set developed for the (A) linear and (B) logarithmic (Horsfall-Barratt) scales to evaluate the severity of Cercospora leaf spot on table beet leaves within the app, Estimate. 
tendency to round the estimates to the nearest 5 or $10 \%$ values was observed, resulting in "knots." Seven values accounted for $52.7 \%$ of the percentage severity estimates: $5,10,15,20,30,40$, and $50 \%$ (Supplementary Fig. S1).

Agreement analyses. A greater frequency of positive absolute errors (overestimation) was detected for the set of 16 leaves with severities $<20 \%$, whereas both positive and negative errors, up to approximately $\pm 40 \%$ points, were depicted for actual severities between 20 and 75\% (Fig. 4A). The direction and magnitude of the errors varied across raters and the actual percentage severity (Fig. 4A). Concordance analysis showed that raters varied in baseline accuracy. In general, a broader range of variability was found in rater precision $(r ; 0.57$ to 0.99$)$ compared with generalized bias $\left(C_{b} ; 0.83\right.$ to 1.0). Therefore, accuracy or overall agreement $\left(\rho_{c}\right)$, which is the product of those two measures, ranged from 0.7 to 0.99 . Four of the 30 raters $(13 \%)$ had accurate estimates $\left(\rho_{c}>0.9\right)$. One-half of the raters showed a baseline accuracy $<0.8$, suggesting a poor innate ability to estimate severity accurately. The remaining (11) raters showed a fair innate ability, with concordance coefficients ranging between 0.8 and 0.9 (Fig. 4B).

Most of the HB ordinal estimates were assigned correctly in the first two grades (smaller intervals) of the scale, whereas raters tended to assign mostly one (eventually two) grade above or below the correct one for the four intermediate grades (larger intervals). For the maximum percentage severity (small intervals), raters tended to assign a higher grade in most cases (Fig. 5A). The overall ( $n=900$ subjects) percentage agreements were 57 and $88.2 \%$ for tolerances of zero or one grade, respectively. The weighted kappa coefficient was estimated as 0.89 ( $95 \%$ confidence interval, 0.87 to 0.90$)$.

When using the $10 \%$ interval scale, most estimates were assigned correctly for the first actual zero to $10 \%$ interval, but in $30 \%$ of the cases, raters assigned severity two grades higher relative to the actual grade. For the remainder of the actual grades, raters tended to assign severity to a higher grade compared with the actual grade. For intervals of 40 to $50 \%$ and 50 to $60 \%$, most assigned grades did not match the actual grade, and only $10 \%$ of the estimates were correct. For the remaining grades, most were incorrectly assigned two grades above or below the actual one (Fig. 5B). The overall percentage agreements were 43 and $85.7 \%$ for tolerances of zero and one grade, respectively. The weighted kappa coefficient was estimated as 0.82 (95\% confidence interval, 0.80 to 0.84 ).

When using the midpoint of the selected score to calculate errors (estimated midpoint minus the actual percentage severity value) of the estimates, an overall trend of overestimating disease severity for the entire range of the HB scale was observed (Fig. 6). Most errors ranged between 10 and $50 \%$. The pattern of overestimation for the LIN scale was similar to that for the HB scale, but underestimation was more frequent at actual severities $<25 \%$, whereas at severities $>25 \%$, underestimation was less pronounced (Fig. 6).

Although raters were instructed to assign any percentage values within the chosen score in the first step, a tendency to assign in "knots" was observed for the HB2- and LIN2-derived data and similar to the unaided estimates (Supplementary Fig. S2). This behavior was noticed irrespective of the scale first used (LIN or HB), but it was more pronounced for LIN2 compared with HB2. On most occasions, raters tended to assign the midpoint of the interval, but on other occasions, the intermediate value within the $10 \%$ interval, such as 45 , $55,65 \%$, and so on, was used, mainly when severity was being assigned $>20 \%$. A broad variation in percentage severity values was observed when assigning values $<10 \%$.

Effect of evaluation systems. There were significant differences in the components of LCC representing generalized bias (systematic and constant bias), precision, and overall agreement when comparing estimates by all raters using the four rating systems within the
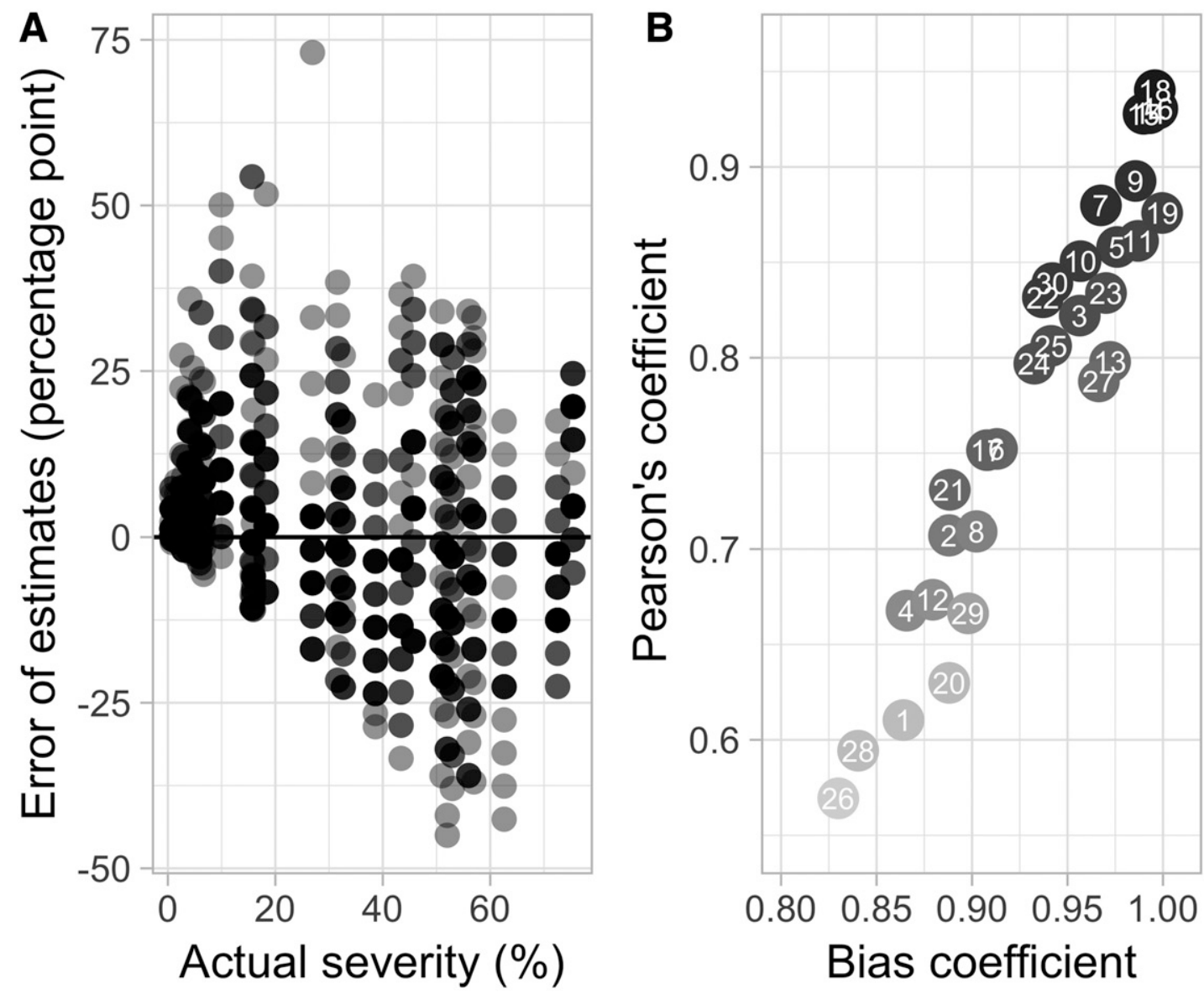

Lin's coef.

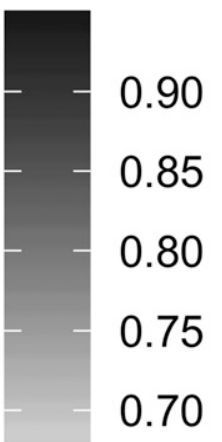

Fig. 4. A, Relationship between percentage point deviation (estimated minus actual severity determined using the Leaf Doctor app) (Pethybridge and Nelson 2015) of estimates of Cercospora leaf spot severities on table beet leaves. B, Relationship between the components of Lin's correlation coefficient (Pearson's correlation coefficient and bias coefficient) across the 30 inexperienced and unaided raters designated by numbers ( 1 to 30 ). 
Estimate app (Table 1). The LIN2 method produced less biased and more precise estimates, and consequently, there was greater concordance of the estimates to the actual values compared with the other three methods, which did not significantly differ from each other or the unaided assessment. Systematic bias in percentage severity estimates was not significantly different $(P>0.05)$ between the estimates conducted using the LIN scales (LIN or LIN2) and the unaided estimates but was significantly reduced in estimations conducted with the HB scale (Table 1). Constant bias was significantly less using the LIN2 method compared with LIN or the HB or HB2 method. Constant bias did not differ between LIN and the unaided estimates (Table 1).

When conditioning the concordance coefficient to the three groups of baseline accuracy, the LIN2-derived estimates showed consistently higher agreement compared with estimates using the other three methods, irrespective of the baseline accuracy. For the other methods, on average, raters with the lowest baseline accuracy benefited from using either method, but both groups exhibited great variability among them. There was no apparent effect of rating method for raters with fair baseline accuracy, but variability was increased compared with that of the aided estimates. Finally, for raters with the highest baseline accuracy, all methods other than LIN2 were detrimental to the accuracy compared with the aided estimates (Fig. 7).

Interrater reliability. Interrater reliability of the estimates also improved with the use of app-aided diagrammatic scales. The OCCC and ICC for the unaided percentage severity estimates were 0.743 and 0.823 , respectively. The OCCC and ICC were at least 0.93 for estimates using the LIN2 method. For the remaining aided evaluations, OCCC and ICC values were $<0.858$ (Table 2).

\section{Discussion}

Traditionally, SADs have been made available in a broad range of print and digital formats, including pocket books, books, technical articles, and peer-reviewed articles, where they have been formally evaluated. They are designed to serve as an aid to visual severity estimation via interpolation and can serve as a platform for training
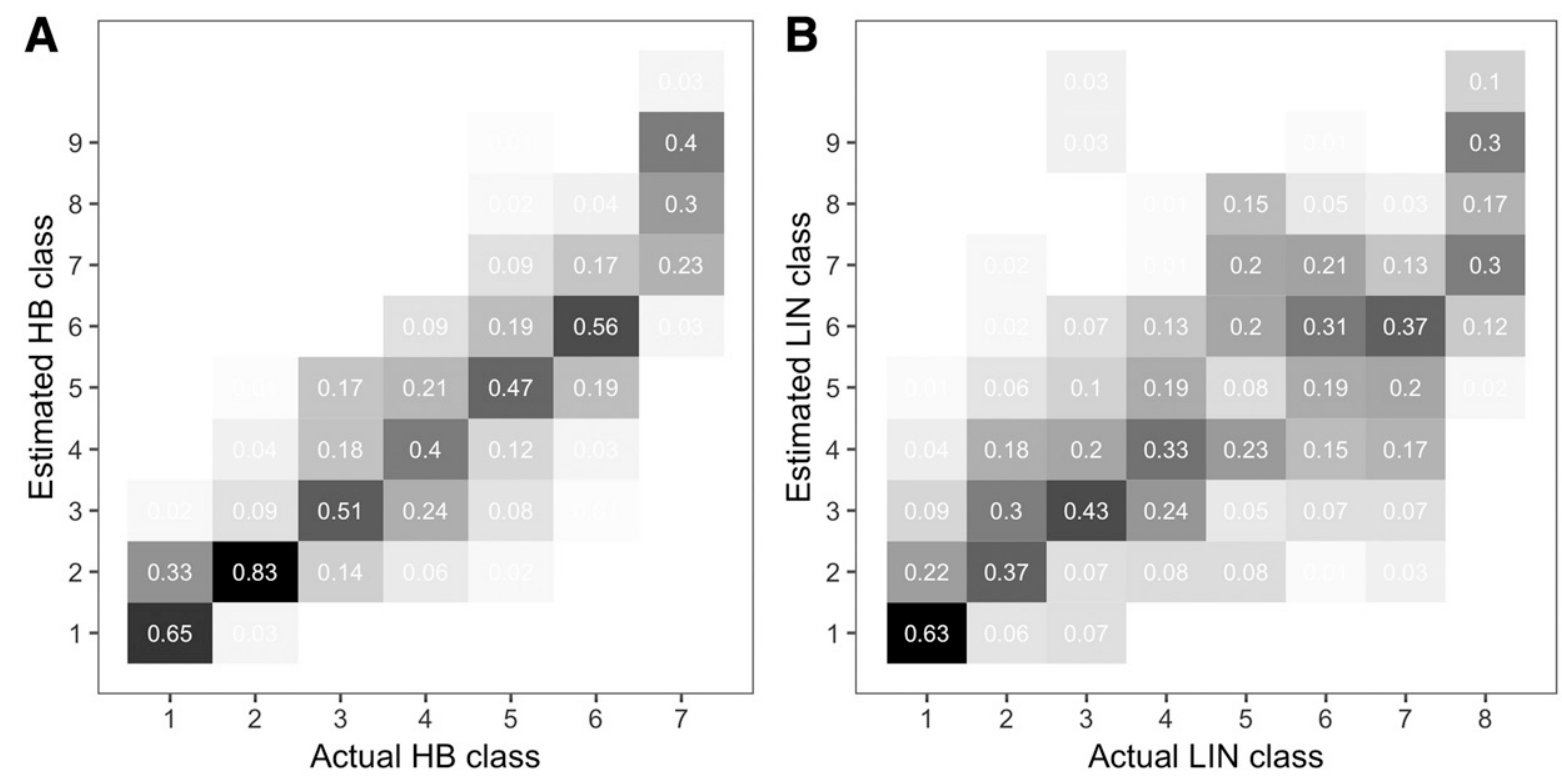

Proportion

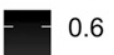

0.4

0.2

0.0

Fig. 5. Heat map depicting the proportion of assigned categories matching the actual category (comprising the actual severity) of two disease scales for the assessment of Cercospora leaf spot on table beet leaves. A, Horsfall-Barratt (HB) scale across 30 inexperienced raters (1 to 30 ). B, 10\% linear interval (linear-based diagrammatic scale [LIN]) scale across 30 inexperienced raters (1 to 30$)$.
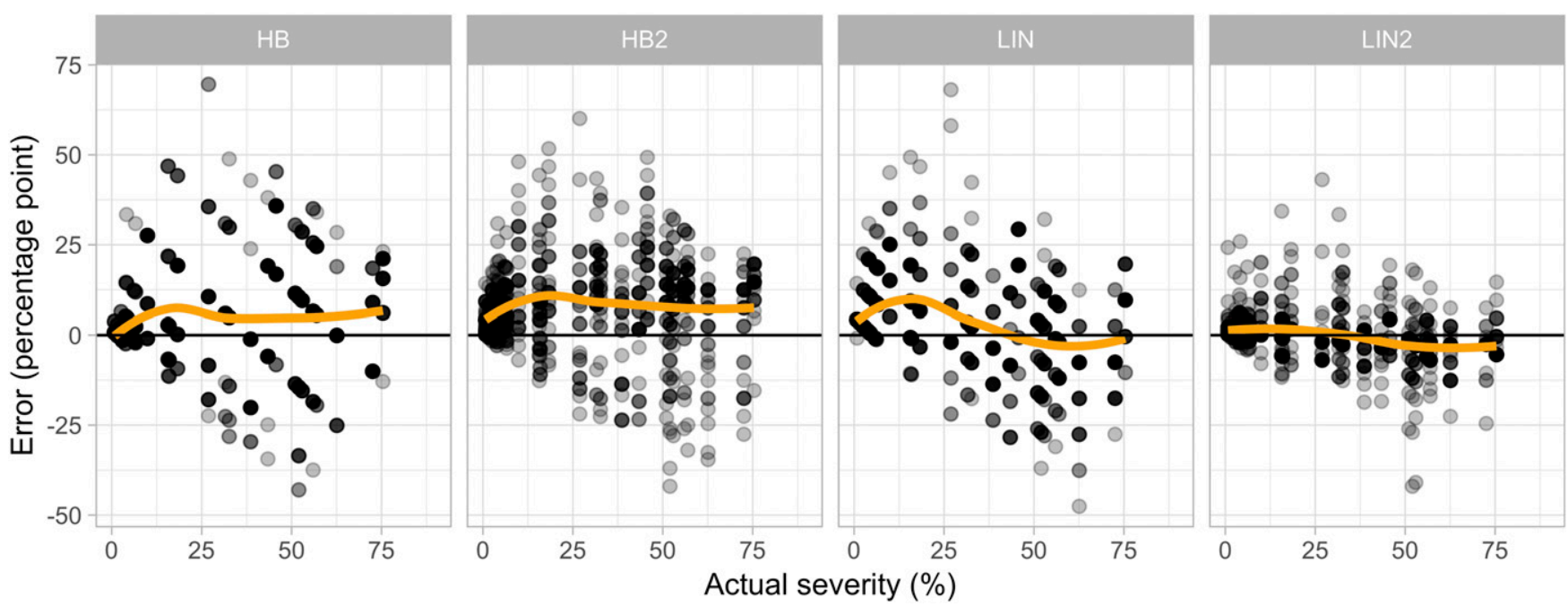

Fig. 6. Relationship between percentage point deviations (midpoint category or nearest percentage severity estimates minus actual severity) across actual severity of Cercospora leaf spot on table beet. Four methods were evaluated based on two disease scales, Horsfall-Barratt (HB) or linear (linear-based diagrammatic scale [LIN]), embedded in the Estimate app (2017 version). In HB and LIN, after category assignment, the midpoint value was used. In HB2 and LIN2, an additional step allowed the rater to assign a specific percentage severity unitary value within the chosen interval of each disease scale. 
sessions. For the latter, computerized severity assessment training programs have been developed to help people improve their ability to estimate disease severity (e.g., PrecisionPro) (Nutter et al. 2016). These earlier tools generated SADs and evaluated interrater and intrarater agreement; these are not intended for use by raters during assessments but are to be used before as a training tool. The Estimate app evaluated in our study is the first SAD-based tool to utilize a handheld device, such as the iPad (Pethybridge and Nelson 2018), thus allowing advantages of portability and a unique human-machine interaction, which were not possible with traditional printed or digital SADs.

We conducted a formal comparison of the different systems available in the first version of the Estimate app (2017 release). The different assessment systems vary in the number of steps and produce two data types representing percentage severity for a classic leaf-spotting disease, CLS of table beet. Results of our analysis showed that only one (LIN2) of the four methods available in the Estimate app significantly improved overall accuracy compared with unaided estimates. We used a large pool of raters who varied in their innate ability to estimate severity accurately. Most previous research on validation of SADs showed a benefit from using the tool, but gains in accuracy and precision vary largely among the studies (E. M. Del Ponte, et al., unpublished data). Gains in accuracy and precision seem to be dependent on (1) rater-related factors, such as the innate ability

Table 2. Interrater reliability of estimates of the percentage severity of Cercospora leaf spot on leaves of table beet across 30 inexperienced raters either unaided or aided by a logarithmic or linear standard area diagram set based on either continuous or ordinal data formats ${ }^{2}$

\begin{tabular}{llcc}
\hline Assessment scale & \multicolumn{1}{c}{ Data type } & ICC & OCCC $\left(\boldsymbol{C}_{\boldsymbol{b}}\right)$ \\
\hline Unaided & Continuous & 0.823 & 0.743 \\
Linear & Ordinal (LIN) & 0.854 & 0.814 \\
Linear & Continuous (LIN2) & 0.937 & 0.930 \\
HB & Ordinal (HB) & 0.849 & 0.820 \\
HB & Continuous (HB2) & 0.859 & 0.835 \\
\hline
\end{tabular}

${ }^{\mathrm{z}} \mathrm{HB}$, Horsfall-Barratt; ICC, intraclass correlation coefficient; LIN, linearbased diagrammatic scale; OCCC, overall concordance correlation coefficient.

Table 1. Effect of scale interval (linear or logarithmic) depicted by the standard area diagrams and effect of the data type (midpoint ordinal or continuous) compared with unaided (UN) estimation of percentage severity of Cercospora leaf spot of table beet by 30 inexperienced raters on components of accuracy, precision, and concordance using Lin's concordance correlation (LCC) ${ }^{\mathrm{y}}$

\begin{tabular}{|c|c|c|c|c|c|c|}
\hline Assessment scale & Data type (method) & Generalized bias $\left(C_{b}\right)$ & Location shift $(\mu)$ & Scale shift (v) & Pearson's $(r)$ & $\operatorname{LCC}\left(\rho_{c}\right)$ \\
\hline Unaided & Continuous (UN) & $0.93 \mathrm{~b}^{\mathrm{z}}$ & $0.017 \mathrm{bc}$ & $0.98 \mathrm{~b}$ & $0.78 \mathrm{~b}$ & $0.84 \mathrm{~b}$ \\
\hline $10 \%$ Linear & Ordinal (LIN) & $0.96 \mathrm{~b}$ & $0.14 \mathrm{~b}$ & $0.95 \mathrm{~b}$ & $0.82 \mathrm{~b}$ & $0.85 \mathrm{~b}$ \\
\hline $10 \%$ Linear & Continuous (LIN2) & $0.99 \mathrm{a}$ & $-0.01 \mathrm{c}$ & $0.95 \mathrm{~b}$ & $0.95 \mathrm{a}$ & $0.96 \mathrm{a}$ \\
\hline $\mathrm{HB}$ & Ordinal (HB) & $0.96 \mathrm{~b}$ & $0.15 \mathrm{~b}$ & $1.17 \mathrm{a}$ & $0.82 \mathrm{~b}$ & $0.86 \mathrm{~b}$ \\
\hline $\mathrm{HB}$ & Continuous (HB2) & $0.94 \mathrm{~b}$ & $0.29 \mathrm{a}$ & $1.12 \mathrm{a}$ & $0.81 \mathrm{~b}$ & $0.86 \mathrm{~b}$ \\
\hline
\end{tabular}

${ }^{\mathrm{y}} \mathrm{HB}$, Horsfall-Barratt; LIN, linear-based diagrammatic scale.

${ }^{\mathrm{z}}$ All probability values $<0.05$ were calculated using a Wald test. Means followed by the same letter within columns are not significantly different (Tukey's honestly significant difference; $P=0.05$ ).
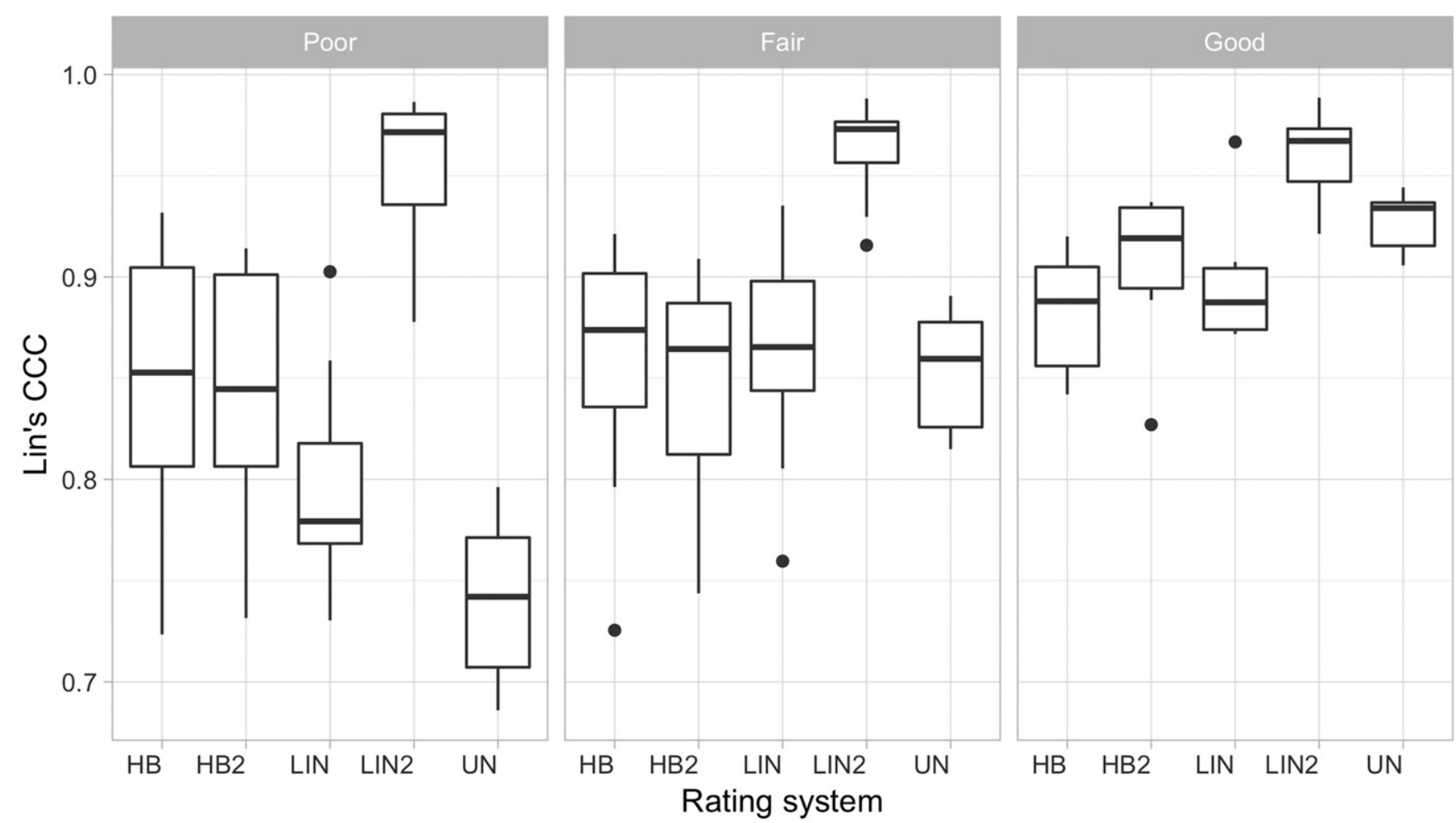

Fig. 7. Distribution of the individual Lin's concordance correlation coefficients (CCCs; $\rho_{c}$ ) for visual severity estimates obtained unaided (UN) or aided by four different rating systems. Two are a single-step assignment of ordinal scores (Horsfall-Barratt [HB; log-based diagrammatic scale] and linear-based diagrammatic scale [LIN]), and two have an additional step for assignment of a unitary percentage severity within the range of the chosen score (HB2 and LIN2). The group of 30 raters was split into three categories of baseline accuracy, which were defined based on accuracy of UN estimates as poor $\left(\rho_{c}<0.8\right)$, fair $\left(0.8 \leq \rho_{c}<0.9\right)$, and good $\left(\rho_{c} \geq 0.9\right)$. 
and previous experience; (2) disease-specific features, including lesion number, pattern, shape, and size; and (3) characteristics of the SAD tool, such as number of diagrams, scale of the increments in severity, representativeness, and overall quality of the diagrams and presentation (Del Ponte et al. 2017). It is not uncommon for additional SAD research to be needed to optimize an available tool, especially in situations where it has been shown not to improve the accuracy of estimates or where multiple SADs may be already prepared for the same disease to ensure local relevance.

The Estimate app presents a novel approach that combines in a single tool different methods for estimation of plant disease severity as ordinal or continuous data and includes (1) a disease scale, (2) SAD/photos of the disease, and (3) NPE-supporting capability. The app also adds interactivity and automation for recording and storing percentage severity estimates. In its most basic application, the Estimate app is no different than a static diagrammatic disease aiding grade selection by the rater using standard area disease images (not a diagram in this case) representing each grade/interval. However, the Estimate app allows choice of ordinal scale interval, either using the HB scale or a $10 \%$ linear scale, for which the midpoint value of the selected interval is compared with the actual percentage severity to determine its impact on accuracy.

We determined that use of the two ordinal disease scales, regardless of the incremental rate (logarithmic or linear), resulted in estimates no more accurate than unaided estimates. This is in agreement with previous research that has reported that estimates based on the HB scale are less accurate or precise compared with direct estimates of percentage severity and may lead to errors in hypothesis testing (Bock et al. 2008, 2009a, 2009b, 2010a; Chiang et al. 2014; Christ 1991).

Linear scales are generally preferred to HB-type logarithmic scales, and a trend of increased usage of linear scales for SAD development has been observed (Del Ponte et al. 2017). However, we did not observe evidence of superiority of the ordinal LIN scale when used in the one-step assessment (10\% interval ordinal scale). In contrast, we determined that either the HB or LIN scale resulted in mismatches between estimated grade and actual grade that affected accuracy because of biases, mostly overestimation, when using the midpoint of the interval. As expected, estimates based on the HB scale resulted in the most disagreements for estimates in the narrow interval ranges of the scale compared with when intervals were wider. With the $10 \%$ interval LIN scale, the greatest mismatch was in the midrange of the scales (40 to 60\%), which suggested that raters had difficulty discerning severity in that range, although there is evidence that raters are able to discern severity more accurately in the midrange (Nutter and Esker 2006). There was a comparatively lower error for grade selection when using the HB scale over a similar range, which may be because of larger interval sizes in the HB scale over this range of severities, compared with the LIN scale. Nonetheless, there was still $<50 \%$ frequency correct grade allocation when using the HB scale. This agrees with previous SAD studies that have shown that errors increase proportionally with increasing actual severity (Bock et al. 2016a). The use of linear scales does not seem to alleviate the problem when using the midpoint interval.

Collectively, especially for raters with fair to good innate accuracy, these results discourage the single-step use of Estimate as an aid for ordinal (midpoint) data assignment but do support its use when estimates are made as a two-step process. Another choice of the nearest unitary percentage severity should be made by the rater. However, when using the HB scale, the accuracy of the two-stage unitary percentage estimates is still lower, and there is no difference from the unaided estimates. This may be because of midrange grades of the HB scale being much larger (compared with the LIN), and when an incorrect grade is selected, the distance between the unitary severity estimate and the actual severity is most often greater, as borne out by our data. However, when using the LIN scale first, despite grade mismatches, the narrower range of the intervals likely allowed raters to select a severity that was relatively closer to the actual severity values. In fact, most of the errors using the LIN2 approach were up to $\sim 10 \%$, whereas the errors using the HB2 approach were as great as $25 \%$.

Our results clearly favor adoption of the two-step process for obtaining the most accurate severity data when using the Estimate app for estimation of severity of CLS. However, our analysis also revealed intricacies of the severity estimations, such as the knots phenomenon as reported in previous studies (Bock et al. 2009b; Hau et al. 1989; Koch and Hau 1980; Schwanck and Del Ponte 2014). The tendency to "round" values was greatest in the unaided estimates (knots spaced at 5\% intervals were most common for estimates of actual severity $>15 \%$ ) and minimized when using the Estimate app during the two-step process when options were narrowed down to only unitary percentage values within the chosen interval. Intriguingly, the value preference did not affect accuracy and precision of the estimates when the LIN scale was chosen. This is likely owing to the narrower range of the intervals in the LIN scale, and therefore, the assigned knots are closer to the actual value. In the Estimate app, the second screen after selecting the ordinal grade shows all unitary percentage values within the interval, but the image for each in that interval is the same. Hence, the estimates are not aided by a standard area diseased image in the second stage. However, this additional processing step may force the rater to consider the evaluation, and there is more opportunity to revise before making the final estimate of severity. As previously stated, the Estimate app is a hybrid approach that incorporates elements of various systems, and additional research is needed to investigate whether accuracy can be improved further with less effort and time taken for the assessment. Although we may confidently recommend it for aiding estimates of percentage severity of CLS and other diseases of similar symptomatology, we cannot conclude that estimates are more accurate compared with the use of a conventional SAD (using the same SADs of the app in print), because this was not included in the study. In either case, raters are not limited to select (unaided) a percentage severity within a chosen interval, but they have at least two reference images as an aid during the specimen assessment process. The dynamics in the Estimate app precludes this option for the rater, and additional research would be instructive to fully explore these issues and propose adjustments in app-based diagrammatic scales.

Raters vary in their innate ability, and the use of the aid may not be of value for some raters who show exceptional ability (Yadav et al. 2013) or are experienced (González-Dominguez et al. 2014). Most previous studies have used a lower number of raters than we used in our study, usually $\sim 10$ raters. Only four studies with at least 24 raters were found in 96 studies (Del Ponte et al. 2017). Few studies have analyzed more thoroughly the effects of SADs considering baseline accuracy of the raters, and most have reported the greatest impact of SAD for raters with the poorest innate ability (Braido et al. 2014; Debona et al. 2015; González-Dominguez et al. 2014; Yadav et al. 2013). Our data corroborate those earlier findings; within our sample of 30 raters, greater gains were found for raters with limited innate ability, regardless of the evaluation system. However, most evaluation systems were detrimental to raters with high baseline accuracy, with the exception of the two-stage assessment using the linear scale. How this is influenced by patterns of disease symptoms is not known, because cross-validation of SADs for the same group of raters assessing symptoms on different pathosystems has not been performed. Raters should receive training with the best methodology available, and the research should ensure that the SAD is not detrimental to innately accurate raters. Whenever possible, raters with greater innate ability to estimate severity accurately should be chosen, and it may be determined that the SAD tool (conventional or within app Estimate based) may not be needed for these raters, especially if it is detrimental, does not increase accuracy, or takes more time.

The new tools for aiding severity estimates using current and future versions of Estimate and other similar apps facilitate research for advancing our understanding of sources of error in estimating severity and provide the ability to optimize support tools. Although visual estimates continue to dominate field experimentation and are expected to persist, it is important to identify new paradigms to bridge the gap between humans and machine; touch screens and 
portable devices are appealing platforms for the SAD technology. Additional testing of app-based SADs should include color and types of images within the SADs, because it is not clear whether true color images are superior to black and white drawings (Schwanck and Del Ponte 2014). Currently, only true color photos are available in the Estimate app. Other unexplored aspects are the number of SADs within this study. Suboptimal diagram numbers may negatively affect efficiency of assessment and the ability of the raters to estimate accurately (Bock et al. 2016b). In our study, the time for assessment was fixed at $10 \mathrm{~s}$. It is unknown whether selecting among 10 categories in such a limited time influenced the quality of the estimates, especially for the two-stage assessment. This remains to be investigated, because the need for bounded assessment times may lead to rounding of severity assessments or haphazard guesses.

Traits of individual raters, including experience, training, and personality, also may significantly affect the accuracy and precision of percentage severity evaluations (Bock et al. 2008; Chiang et al. 2014; Nutter et al. 1993). We aimed to minimize these effects by using only inexperienced raters, but we found that, within this group, there were raters with extraordinary ability to estimate severity accurately; use of the Estimate app could result in a detrimental effect. For the case of CLS, estimating percentage area severity offers substantial time savings compared with counting lesions. For example, in recent studies, the average number of CLS lesions per leaf in nontreated plots was at least 200 at the end of the season (Pethybridge et al. 2017). To adequately account for small-scale heterogeneity within plots, lesion counts or estimations of percentage severity must be made on multiple sampling units (i.e., leaves). Counting 200 lesions of CLS ( $\sim 85 \%$ severity on a leaf of table beet cultivar Ruby Queen) (S. J. Pethybridge, unpublished data) on a single leaf can require up to $8 \mathrm{~min}$. It is thus a substantial time constraint. Moreover, percentage severity estimation was not compromised when CLS was severe, yet coalescing of lesions can result in error in lesion counts. Therefore, results suggest that estimating percentage severity as continuous data in $1 \%$ increments using linear SADs provides improved accuracy and precision of estimates across the range of severity and thereby, benefits CLS-related research on table beet.

\section{Acknowledgments}

We thank the 30 anonymous raters for donating their time to this project.

\section{Literature Cited}

Abawi, G. S., Kikkert, J. R., Moktan, K., Lange, H. W., and Smart, C. D. 2014. First report of resistance to Quadris among populations of Cercospora beticola causing leaf spot of table beet in New York State. Phytopathology 104:S1.1.

Abawi, G. S., Ludwig, J. W., and Gugino, B. K. 2005. Evaluation of fungicides for the control of pocket rot and leaf spot of table beet, 2004. Plant Dis. Manage. Rep. 60:V146.

Angelotti, F., Scapin, C. R., Tessmann, D. J., Vida, J. B., Oliveira, R. R., and Canteri, M. G. 2008. Diagrammatic scale for assessment of grapevine rust. Trop. Plant Pathol. 33:439-443.

Baayen, R. H., Davidson, D. J., and Bates, D. M. 2008. Mixed-effects modeling with crossed random effects for subjects and items. J. Mem. Lang. 59:390-412.

Barnhart, H. X., Haber, M., and Song, J. 2002. Overall concordance correlation coefficient for evaluating agreement among multiple observers. Biometrics 58:1020-1027.

Bates, D. M., and Sarkar, D. 2007. Lme4: Linear Mixed-Effects Models Using S4 Classes, R package version 0.99875-6.

Bock, C. H., Chiang, K.-S., and Del Ponte, E. M. 2016a. Accuracy of plant specimen disease severity estimates: Concepts, history, methods, ramifications and challenges for the future. CAB Rev. 11:1-21.

Bock, C. H., Gottwald, T. R., Parker, P. E., Cook, A. Z., Ferrandino, F., Parnell, S., and van den Bosch, F. 2009a. The Horsfall-Barratt scale and severity estimates of citrus canker. Eur. J. Plant Pathol. 125:23-38.

Bock, C. H., Gottwald, T. R., Parker, P. E., Ferrandino, F., Welham, S., van den Bosch, F., and Parnell, S. 2010a. Some consequences of using the HorsfallBarratt scale for hypothesis testing. Phytopathology 100:1030-1041.

Bock, C. H., Hotchkiss, M. W., and Wood, B. W. 2016b. Assessing disease severity: Accuracy and reliability of rater estimates in relation to number of diagrams in a standard area diagram set. Plant Pathol. 65:261-272.

Bock, C. H., Parker, P. E., Cook, A. Z., and Gottwald, T. R. 2008. Characteristics of the perception of different severity measures of citrus canker and the relationships between the various symptom types. Plant Dis. 92:927-939.
Bock, C. H., Parker, P. E., Cook, A. Z., Riley, T., and Gottwald, T. R. 2009b. Comparison of assessment of citrus canker foliar symptoms by experienced and inexperienced raters. Plant Dis. 93:412-424.

Bock, C. H., Poole, G. H., Parker, P. E., and Gottwald, T. R. 2010b. Plant disease severity estimated visually, by digital photography and image analysis, and by hyperspectral imaging. Crit. Rev. Plant Sci. 29:59-107.

Braido, R., Gonçalves-Zuliani, A. M. O., Nocchi, P. T. R., Belasque, J., Jr., Janeiro, V., Bock, C. H., and Nunes, W. M. C. 2014. A standard area diagram set to aid estimation of the severity of Asiatic citrus canker on ripe sweet orange fruit. Eur. J. Plant Pathol. 141:327-337.

Chiang, K. S., Liu, S. C., Bock, C. H., and Gottwald, T. R. 2014. What interval characteristics make a good categorical disease assessment scale? Phytopathology 104:575-585.

Christ, B. J. 1991. Effect of disease assessment method on ranking potato cultivars for resistance to early blight. Plant Dis. 75:353-356.

Correia, K. C., de Queiroz, J. V. J., Martins, R. B., Nicoli, A., Del Ponte, E. M., and Michereff, S. J. 2017. Development and evaluation of a standard area diagram set for the severity of Phomopsis leaf blight on eggplant. Eur. J. Plant Pathol. 149:269-276.

De Coninck, B. M. A., Amand, O., Delauré, S. L., Lucas, S., Hias, N., Weyens, G., Mathys, J., De Bruyne, E., and Cammue, B. P. A. 2012. The use of digital image analysis and real-time PCR fine-tunes bioassays for quantification of Cercospora leaf spot disease in sugar beet breeding. Plant Pathol. 61:76-84.

Debona, D., Nascimento, K. J. T., Rezende, D., Rios, J. A., Bernardeli, A. M. A. Silva, L. C., and Rodrigues, F. A. 2015. A set of standard area diagrams to assess severity of frogeye leaf spot on soybean. Eur. J. Plant Pathol. 142:603-614

Del Ponte, E. M., Pethybridge, S. J., Bock, C. H., Michereff, S. J., Machado, F. J., and Spolti, P. 2017. Standard area diagram aids for aiding severity estimation: Scientometrics, pathosystems and methodological trends in the last 25 years. Phytopathology 107:1161-1174.

Dolinski, M. A., Duarte, H. S. S., da Silva, J. B., and May de Mio, L. L. 2017 Development and validation of a standard area diagram set for assessment of peach rust. Eur. J. Plant Pathol. 148:817-824.

Duarte, H. S. S., Zambolin, L., Capucho, A. S., Junior, A. F. N., Rosado, A. W. C. Cardoso, C. R., Paul, P. A., and Mizubuti, E. S. G. 2013. Development and validation of a set of standard area diagrams to estimate severity of potato early blight. Eur. J. Plant Pathol. 137:249-257.

Franc, G., and Stump, W. L. 2010. Cercospora leaf spot management with foliar fungicide programs, 2009. Plant Dis. Manage. Rep. 4:FC006.

Franc, G. D. 2010. Ecology and epidemiology of Cercospora beticola. Pages 7-19 in: Cercospora Leaf Spot of Sugar Beet and Related Species. R. T. Lartey, J. J. Weiland, L. Panella, P. W. Crous, and C. E. Windels, eds. The American Phytopathological Society Press, St. Paul, MN.

Gamer, M., Lemon, J., Fellows, I., and Singh, P. 2012. irr: Various Coefficients of Interrater Reliability and Agreement. R package version 0.84. https://cran.rproject.org/web/packages/irr/index.html

González-Dominguez, E., Martins, R. B., Del Ponte, E. M., Michereff, S. M., Garcia-Jiménez, J., and Armengol, J. 2014. Development and validation of a standard area diagram set to aid assessment of severity of loquat scab on fruit. Eur. J. Plant Pathol. 139:413-422.

Gugino, B., Ludwig, L. W., and Abawi, G. S. 2008. Evaluation of fungicides for the control of pocket rot and leaf spot of table beet, 2007. Plant Dis. Man. Rep. 2:V156.

Hau, B., Kranz, J., and Konig, R. 1989. Fehler beim Schatzen von Befallsstarken bei Pflanzenkrankheiten. Z. Pflkrankh. Pflschutz. 96:649-674.

Horsfall, J. G., and Barratt, R. W. 1945. An improved grading system for measuring plant disease. Phytopathology 35:655.

James, W. C. 1971. An illustrated series of assessment keys for plant diseases, their preparation and usage. Can. Plant Dis. Surv. 51:39-65.

James, W. C. 1974. Assessment of plant diseases and losses. Annu. Rev. Phytopathol. 12:27-48.

Kleinwanzleber Saatzucht Ag. 1970. Einbeck. Cercospora. Kleinwanzleber Saatzucht Ag. Einbeck Rabbethge and Geisecke.

Koch, H., and Hau, B. 1980. Ein psychologischer aspect beim schatzen von pflanzenkrankheiten. Z. Pflkrankh. Pflschutz 87:587-593.

Koike, S. T., du Toit, L. J., and Abawi, G. S. 2010. Cercospora leaf spot of vegetable crops in the Chenopodiaceae. Pages 91-96 in: Cercospora Leaf Spot of Sugar Beet and Related Species. R. T. Lartey, J. J. Weiland, L. Panella, P. W. Crous, and C. E. Windels, eds. The American Phytopathological Society Press, St. Paul, MN.

Lenth, R. V. 2016. Least-squares means: The R Package lsmeans. J. Stat. Softw. 69:1-33.

Lin, L. I.-K. 1989. A concordance correlation coefficient to evaluate reproducibility. Biometrics 45:255-268.

Madden, L. V., Hughes, G., and van den Bosch, F. 2007. The Study of Plan Disease Epidemics. APS Press, St. Paul, MN.

Martire, R. L. 2017. rel: Reliability Coefficients. R package version 1.3.1. https:// cran.r-project.org/web/packages/rel/index.html

May de Mio, L. L., de Oliveira, R. A., Floriani, A. M. V., Schuber, J. M., Poltronieri, A. S., de Araujo, M. A., and Tratch, R. 2008. Proposal of scale diagrammatic for quantification of Cercospora of beet. Sci. Agr. 9: 331-337.

McKay, M. B., and Pool, V. W. 1918. Field studies of Cercospora beticola. Phytopathology 8:119-136. 
Nutter, F. W., Jr., Eggenberger, S. K., and Streit, A. J. 2016. Disease severity assessment training using DiseasePro. Pages 189-196 in: Exercises in Plant Disease Epidemiology, 2nd Ed. The American Phytopathological Society Press, St. Paul, MN.

Nutter, F. W., Jr., and Esker, P. D. 2006. The role of psychophysics in phytopathology: The Weber-Fechner law revisited. Eur. J. Plant Pathol. 114:199-213.

Nutter, F. W., Jr., Esker, P. D., and Coelho Netto, R. A. 2006. Disease assessment concepts and the advancements made in improving the accuracy and precision of plant disease data. Eur. J. Plant Pathol. 115:95-103.

Nutter, F. W., Jr., Gleason, M. L., Jenco, J. H., and Christians, N. C. 1993. Assessing the accuracy, intra-rater repeatability and the inter-rater reliability of disease assessment systems. Phytopathology 83:806-812.

Pethybridge, S. J., Kikkert, J. R., Hanson, L. E., and Nelson, S. C. 2018. Challenges and prospects for building resilient disease management strategies and tactics for the New York table beet industry. Agronomy (Basel) 8:112.

Pethybridge, S. J., and Nelson, S. C. 2015. Leaf Doctor: A new portable application for quantifying plant disease severity. Plant Dis. 99: 1310-1316.

Pethybridge, S. J., and Nelson, S. C. 2018. Estimate, a new iPad application for assessment of plant disease severity using photographic standard area diagrams. Plant Dis. 102:276-281.

Pethybridge, S. J., Vaghefi, N., and Kikkert, J. R. 2016. Efficacy of fungicides for the control of Cercospora leaf spot in processing table beet, 2015. Plant Dis. Manage. Rep. 10:V003.

Pethybridge, S. J., Vaghefi, N., and Kikkert, J. R. 2017. Management of Cercospora leaf spot in conventional and organic table beet production. Plant Dis. 101:1642-1651.

R Core Team. 2016. R: A Language and Environment for Statistical Computing. The R Foundation for Statistical Computing, Vienna, Austria.
Rios, J., Debona, D., Duarte, H. S. S., and Rodrigues, F. A. 2013. Development and validation of a standard area diagram to assess blast severity on wheat leaves. Eur. J. Plant Pathol. 136:603-611.

Schwanck, A. A., and Del Ponte, E. M. 2014. Accuracy and reliability of severity estimates using linear or logarithmic disease diagram sets in true colour or black and white: A study case for rice brown spot. J. Phytopathol. 162: 670-682.

Shoukri, M. M., and Pause, C. A. 1999. Statistical Methods for Health Science, 2nd Ed. CRC Press, Boca Raton, FL.

Sim, J., and Wright, C. C. 2005. The kappa statistic in reliability studies: Use, interpretation, and sample size requirements. Phys. Ther. 85:257-268.

Stevenson, W. R., James, R. V., and Rand, R. E. 2003. Evaluation of fungicides to control Cercospora leaf spot on table beet - Hancock, 2002. Plant Dis. Manage. Rep. 58:V042.

Stivers, L. 2001. Crop profile: Beets in New York. Cornell Cooperative Extension Bulletin. http://pmep.cce.cornell.edu/fqpa/crop-profiles/beet.html

Stump, W. 2015. Management of Cercospora leaf spot with foliar fungicide programs, 2014. Plant Dis. Manage. Rep. 9:FC125.

Trueman, C. 2014. Evaluation of fungicides for management of Cercospora leaf spot in sugarbeet, 2013. Plant Dis. Man. Rep. 8:FC172.

Trueman, C., and Burlakoti, R. R. 2015. Evaluation of products for management of Cercospora leaf spot in sugar beet, 2014. Plant Dis. Manage. Rep. 9:FC009.

Vereijssen, J., Schneider, J. H. M., Termorshuizen, A. J., and Jeger, M. J. 2003 Comparison of two disease assessment keys to assess Cercospora leaf spot in sugar beet. Crop Prot. 22:201-209.

Weiland, J., and Koch, G. 2004. Sugar beet leaf spot disease (Cercospora beticola Sacc.). Mol. Plant Pathol. 5:157-166.

Yadav, N. V. S., de Vos, S. M., Bock, C. H., and Wood, B. W. 2013. Development and validation of standard area diagrams to aid assessment of pecan scab symptoms on fruit. Plant Pathol. 62:325-335. 